Check for updates

Cite this: RSC Adv., 2018, 8, 19917

\section{Removal of methylene blue from aqueous solution by cattle manure-derived low temperature biochar}

\author{
Yao Zhu, ${ }^{a}$ Baojun Yi, (D)*ab Qiaoxia Yuan, ${ }^{\text {ab }}$ Yunlian Wu, ${ }^{a}$ Ming Wang ${ }^{\text {ab }}$ \\ and Shuiping Yan $^{\mathrm{ab}}$
}

Biochar is a low cost and renewable adsorbent which can be used to remove dye from wastewater. Cattle manure-derived low temperature biochar (CMB) was studied to remove methylene blue (MB) from aqueous solution in this paper. The effect of factors including initial concentration of $M B$, dosage, contact time, and $\mathrm{pH}$ on the adsorption properties of $\mathrm{MB}$ onto biochar were studied. Characterization of the $\mathrm{CMB}$ and $\mathrm{MB}$ adsorbed on CMB was performed using techniques including BET, FTIR and SEM. The adsorption isotherm, kinetics, thermodynamics and mechanism were also studied. The results showed the equilibrium data were well fitted to the Langmuir isotherm model, and the saturation adsorption capacity of $\mathrm{CMB}_{200}$ was $241.99 \mathrm{mg} \mathrm{g}^{-1}$. Pseudo-second order kinetics was the most suitable model for describing the adsorption of $M B$ onto biochar. The adsorption thermodynamics of $M B$ on biochar showed that the adsorption was a spontaneous and endothermic process. Through zeta potential measurement, Boehm titration, cation exchange, deashing and esterification experiments, the importance of ash to adsorption was verified, as well as the adsorption mechanism. The adsorption mechanism of $\mathrm{MB}$ on $\mathrm{CMB}_{200}$ involved cation exchange, electrostatic interaction, hydrogen bonding, physical effects and others. This work shows that $\mathrm{CMB}_{200}$ holds promise to act as an effective adsorbent to remove $M B$ in wastewater.
Received 9th April 2018 Accepted 15th May 2018 DOI: 10.1039/c8ra03018a rsc.li/rsc-advances considerably more important than high porosity in the adsorption process. ${ }^{14}$

With the expansion of large-scale farms, the disposal of livestock manure is becoming a major problem. ${ }^{15,16}$ In a previous study, livestock manure-derived biochar was used for soil improvement and soil pollution control. ${ }^{17}$ However, the amount of livestock manure produced by large-scale farms exceeds the needs of local farmlands. In addition, direct utilization as fertilizer generates unpleasant smells. The anaerobic fermentation of livestock and poultry manure can reduce the smell, but the process is too slow. Therefore, it is urgent to find a new method of fecal treatment and resource utilization. ${ }^{18}$

In experiments comparing the use of cattle manure (CM) and rice husks for heavy metal adsorption, it was found that $\mathrm{CM}$ had better adsorption characteristics than rice husks, ${ }^{19}$ indicating that CM had good adsorption properties. Cattle manure biochar (CMB) is particularly effective for treatment of heavy metals, ${ }^{19-21}$ and represents a new form of resource utilization of CM. As was shown in a previous study, dairy manure (DM) biochar presents a high adsorption efficiency of $\mathrm{Cu}, \mathrm{Zn}$, and $\mathrm{Cd}$. The adsorption efficiency of DM biochar prepared at $350{ }^{\circ} \mathrm{C}$ is higher than that prepared at $200{ }^{\circ} \mathrm{C}^{21}$ The precipitation-based mechanism is the main reason for the high efficiency of the heavy metal adsorption of $\mathrm{CMB}$, and its effectiveness is attributed to the high ash content of $\mathrm{CMB}^{21}$ Studies of CMB have focused on the adsorption of heavy metals, while the study of the adsorption of
${ }^{a}$ College of Engineering, Huazhong Agricultural University, No. 1, Shizishan Street, Hongshan District, Wuhan, 430070, P. R. China. E-mail: bjyi@mail.hzau.edu.cn; Fax: +8627 87282120; Tel: +862787282120

${ }^{b}$ Key Laboratory of Agricultural Equipment in the Mid-lower Yangtze River, Ministry of Agriculture, Wuhan, 430070, P. R. China 
Table 1 Proximate analysis and ultimate analysis of samples

\begin{tabular}{|c|c|c|c|c|c|c|c|c|c|c|}
\hline \multirow[b]{2}{*}{ No. } & \multirow[b]{2}{*}{ Sample } & \multicolumn{4}{|c|}{ Proximate analysis (wt\% ad) } & \multicolumn{5}{|c|}{ Ultimate analysis (wt\% daf) } \\
\hline & & M & $\mathrm{VM}$ & $\mathrm{FC}$ & A & $\mathrm{C}$ & $\mathrm{H}$ & $\mathrm{O}^{a}$ & $\mathrm{~N}$ & $\mathrm{~S}$ \\
\hline 2 & SD & 9.60 & 76.08 & 13.86 & 0.47 & 59.67 & 7.34 & 32.55 & 0.41 & 0.03 \\
\hline 3 & CS & 9.80 & 67.19 & 19.50 & 3.51 & 47.48 & 6.28 & 44.42 & 1.21 & 0.61 \\
\hline 4 & RS1 & 9.04 & 77.38 & 6.77 & 6.81 & 46.93 & 6.33 & 45.46 & 0.52 & 0.76 \\
\hline
\end{tabular}

organic matter has concentrated on straw biochar., ${ }^{1,2}$ Thus, there has been little research on the adsorption of organic matter by CMB. An earlier experiment compared the use of washed and unwashed peanut straw for the adsorption of methyl violet, and found a weak adsorption ability of the washed peanut straw biochar, which showed that the existence of soluble salts in biochar can improve its ability to adsorb organics. ${ }^{22}$ Elsewhere, the adsorption performance of biochar modified with phosphate and carbonate was improved greatly; therefore, the soluble alkali salts in ash play a role in ion exchange in the adsorption process. Ash content is beneficial to the adsorption of organic matter, so the high ash content of CM makes it a promising research object. ${ }^{23}$

Leng used sludge biochar to adsorb dye, and found that the adsorption performance of the sludge biochar prepared at $260{ }^{\circ} \mathrm{C}$ was superior to that at $340{ }^{\circ} \mathrm{C} \cdot{ }^{14}$ Adsorption of lead by sugarcane biochar is facilitated at low temperature, because the functional groups on the surface of high temperature biochar are less abundant than those of low temperature biochar. ${ }^{24}$ Preparing $\mathrm{CMB}$ at low temperature is more economical in addition to the improvements in its practical performance..$^{25}$ $\mathrm{CM}_{300}$ has good adsorption properties for alastin, ${ }^{26}$ but the underlying mechanism has not been analyzed. However, the clarification of the reaction mechanism is very important for the removal of organic matter by $\mathrm{CMB} .{ }^{25}$

To address the lack of research on the adsorption of organic matter by CMB, especially for CMB as an adsorbent prepared under low temperature conditions, this study carried out experiments on the adsorption of $\mathrm{MB}$ by low temperature $\mathrm{CMB}$ from three aspects: (1) the feasibility of low temperature pyrolysis to prepare $\mathrm{CMB}$ as an adsorbent for removal of $\mathrm{MB}$ from aqueous solution; (2) the adsorption properties of MB and the optimum parameters; (3) possible mechanisms of action.

\section{Experimental}

\subsection{Materials and pretreatment}

CM was obtained from Wuhan Jiangxia District Crusades Animal Husbandry Limited Liability Company (Wuhan, China). Fresh CM samples were dried, crushed, sieved through 60-mesh sieves and oven dried at $105{ }^{\circ} \mathrm{C}$ for $24 \mathrm{~h}$ to ensure drying, then crushed to a particle size between those of 60-mesh sieves and 200-mesh sieves. Because most research has focused on the adsorption of organic matter by straw biochar, ${ }^{1,2}$ for the purpose of comparison with the data on conventional methods, five kinds of agricultural and forestry wastes including sawdust (SD), cotton stalk (CS), rape stalk (RS1), rice stalk (RS2) and rice chaff (RC) were selected as adsorbents for control experiments to determine the adsorption ability of CM in this paper. The CS, RS1, and RS2 were taken from a location in Hubei. The SD and $\mathrm{RC}$ were purchased from a wood processing plant and rice processing plant, respectively. The stalks were also broken up, dried and sieved. As shown in Table 1, all the samples in this study had about $9 \%$ moisture content on an air-dried basis, while CM had a lower volatile matter (VM) content and a higher ash (A) content than the other samples. The contents of A in SD and CS were low, and the fixed carbon (FC) contents of RS1 and RS2 were low. The CM contained relatively low contents of C and $\mathrm{H}$ and higher contents of $\mathrm{O}$ and $\mathrm{N}$. MB was purchased from Sinopharm and used without further purification. The molecular weight of $\mathrm{MB}$ is $373.9 \mathrm{~g} \mathrm{~mol}^{-1}$. Ultrapure water was used to prepare all sorbent solutions and wash all vessels. All solutions were prepared by diluting the stock solution with ultrapure water to the needed concentration.

\subsection{Preparation and characterization of adsorbent}

A square crucible of $120 \times 60 \times 20 \mathrm{~mm}$ containing $2 \mathrm{~g}$ sample was placed in a tube furnace, and torrefied in a $\mathrm{N}_{2}$ atmosphere at $200{ }^{\circ} \mathrm{C}$ for 30 minutes. Before the reaction, $\mathrm{N}_{2}$ gas was supplied into the tube furnace in advance to ensure an inert gas atmosphere. After torrefaction, the sample was cooled in a $\mathrm{N}_{2}$ container, weighed, packed in a sealed bag and stored in a dry container. All of the biochars are denoted with the suffix "B", for example the CM biochar is denoted as CMB. The different torrefaction temperatures are indicated in subscript after the suffix, for example the $\mathrm{CM}$ biochar prepared at $200{ }^{\circ} \mathrm{C}$ is denoted as $\mathrm{CMB}_{200}$. In addition to the biochar prepared at $200{ }^{\circ} \mathrm{C}$, samples of biochar were also prepared by pyrolysis at $800{ }^{\circ} \mathrm{C}$ for comparison with the high-temperature biochars reported in the literature. Other than increasing the temperature to $800{ }^{\circ} \mathrm{C}$, the pyrolysis process was similar to that of torrefaction. In order to analyze the characteristics of $\mathrm{CMB}$ after adsorption, samples were prepared after adsorption for $80 \mathrm{~min}$ and 180 min, which were denoted as $\mathrm{CMB}_{200-80}$ and $\mathrm{CMB}_{200-180}$ respectively. Meanwhile, in order to study the effect of washing 
Table 2 Boehm titration and zeta potential for CMB

\begin{tabular}{llllll}
\hline Sample & $\begin{array}{l}\text { Carboxyl } \\
\left(\mathrm{mmol} \mathrm{g}^{-1}\right)\end{array}$ & $\begin{array}{l}\text { Lactonic } \\
\left(\mathrm{mmol} \mathrm{g}^{-1}\right)\end{array}$ & $\begin{array}{l}\text { Phenolic } \\
\left(\mathrm{mmol} \mathrm{g}^{-1}\right)\end{array}$ & $\begin{array}{l}\text { Basic functional } \\
\text { groups }\left(\mathrm{mmol} \mathrm{g}^{-1}\right)\end{array}$ & $\begin{array}{l}\text { Zeta potential } \\
(\mathrm{mV})\end{array}$ \\
\hline $\mathrm{CMB}_{200}$ & 0.375 & 0.1875 & 0.4375 & 0.875 & -39 \\
$\mathrm{CMB}_{800}$ & 0.125 & 0.125 & 0.25 & 1 & 4.4 \\
\hline
\end{tabular}

on the surface adsorption properties, a sample of char was washed after 180 min adsorption, and labeled as $\mathrm{CMB}_{200-180-\mathrm{w}}$.

An Accelerated Surface Area and Porosimetry System (ASAP 2020) was used for analysing the specific surface area and pore structure. The $\mathrm{N}_{2}$ adsorption method was used in the experiment, in which the specific surface area was calculated with the Brunauer-Emmett-Teller (BET) method based on adsorption isotherms. A VERTEX 70 Fourier transform infrared (FTIR) spectrometer from Bruker (Germany) was used to analyze the functional groups on the surface. Char samples were mixed with $\mathrm{KBr}$ at a ratio of $1: 180$ and the wavenumber range of infrared scanning was $400-4000 \mathrm{~cm}^{-1}$. The zeta potential was analyzed by the methods described in previous references. ${ }^{27}$ The contents of oxygen-containing functional groups of the samples were determined using Boehm titration by a standard method. ${ }^{24}$ The extent of cation exchange was determined after the reaction, by the method described in previous references. ${ }^{\mathbf{1 4}}$

The method of deashing by HCl-HF washing has been described elsewhere. ${ }^{28}$ The carboxyl groups on the surface of CM were removed by esterification, and the adsorption ability of the modified CM was experimentally determined to deduce the effect of the surface carboxyl groups during adsorption. The esterification of the dried biomass was carried out according to a method described elsewhere. ${ }^{29}$

\subsection{Adsorption procedure}

Adsorption experiments were performed in a laboratory water bath shaker. The adsorbent and the solution were placed in a $50 \mathrm{~mL}$ centrifuge tube, the volume of the reaction solution was maintained at $20 \mathrm{~mL}$, and the amount of the adsorbent was $0.025 \mathrm{~g}$. The mixture was subjected to constant-temperature shaking adsorption at $300 \mathrm{rpm}$ for 80 minutes. Before each measurement, the measuring instruments were calibrated. After the end of adsorption, the solution was centrifuged at $4000 \mathrm{rpm}$ for 15 minutes, and the supernatant was diluted and measured at the range of $0 \mathrm{mg} \mathrm{L}^{-1}$ to $10 \mathrm{mg} \mathrm{L}^{-1}$. The $\mathrm{MB}$ concentration in solution was analyzed using a UV spectrophotometer (UH5300, HITACHI) by monitoring the absorbance changes at the wavelength of $670 \mathrm{~nm} .^{30}$

Adsorption isotherm experiments were performed by placing $20 \mathrm{~mL} \mathrm{MB}$ into a $50 \mathrm{~mL}$ centrifuge tube, then adding $0.025 \mathrm{~g}$ of biochar to the solution and shaking for 24 hours in a laboratory water bath shaker until equilibrium. The experiment was repeated three times. The equilibrium adsorption capacity $q_{\mathrm{e}}$ $\left(\mathrm{mg} \mathrm{g}^{-1}\right)$ was calculated by the following formula: ${ }^{31}$

$$
q_{\mathrm{e}}=\frac{\left(C_{0}-C_{\mathrm{e}}\right) V}{W}
$$

The removal rate formula is:

$$
R=\frac{100\left(C_{0}-C_{t}\right)}{C_{0}}
$$

$C_{0}$ and $C_{\mathrm{e}}\left(\mathrm{mg} \mathrm{L}^{-1}\right)$ are the liquid phase concentrations of $\mathrm{MB}$ at the initial time and equilibrium, respectively. $V$ is the volume of the solution (L) and $W$ is the mass of the dry adsorbent (g).

The kinetics were studied by a similar procedure to the equilibrium experiments. The solution was extracted and analyzed at different times (30 min, $90 \mathrm{~min}, 240 \mathrm{~min}, 1200 \mathrm{~min}$ and $1440 \mathrm{~min})$. The amount of adsorption $q_{t}\left(\mathrm{mg} \mathrm{g}^{-1}\right)$ at $t \mathrm{~min}$ was calculated by the following formula: ${ }^{3}$

$$
q_{t}=\frac{\left(C_{0}-C_{t}\right) V}{W}
$$

$C_{0}$ and $C_{t}\left(\mathrm{mg} \mathrm{L}^{-1}\right)$ are the initial liquid phase concentration and the concentration at time $t$. $V$ is the volume of solution (L) and $W$ is the mass of dry adsorbent $(\mathrm{g})$.

\section{Results and discussion}

\subsection{Characterization of CM and CMB}

3.1.1. Boehm titration and zeta potential. The oxygencontaining functional groups on the surface of CMB determine the acidity and adsorption properties of the surface. The total acidity and total alkalinity of CMB were determined by Boehm titration. From Table 2, the increase of pyrolysis temperature caused a decrease in total acidity, accompanied by a reduction of the amount of oxygen-containing functional groups.

The protonation and deprotonation of functional groups create a net charge on surface carbons, forming an electrical double layer in solution near the surface. ${ }^{22}$ The $\mathrm{pH}_{\mathrm{IEP}}$, i.e. the $\mathrm{pH}$ at which the charge on the surface carbons is zero, reflects the combined influence of all the functional groups. With the increase of pyrolysis temperature, the $\mathrm{pH}_{\mathrm{IEP}}$ of biochar increased, but remained very low compared with activated carbon. Combined with the results of Boehm titration, it can be inferred that the low $\mathrm{pH}_{\mathrm{IEP}}$ of biochar is due to the surface functional groups. ${ }^{32}$

The zeta potential of $\mathrm{CMB}$ is negative, indicating that the surface of CMB is negatively charged. The zeta potential of the biochar decreased with increased pyrolysis temperature, i.e. the biochars produced at lower temperatures carried more negative surface charges than those produced at higher temperatures, ${ }^{33}$ 


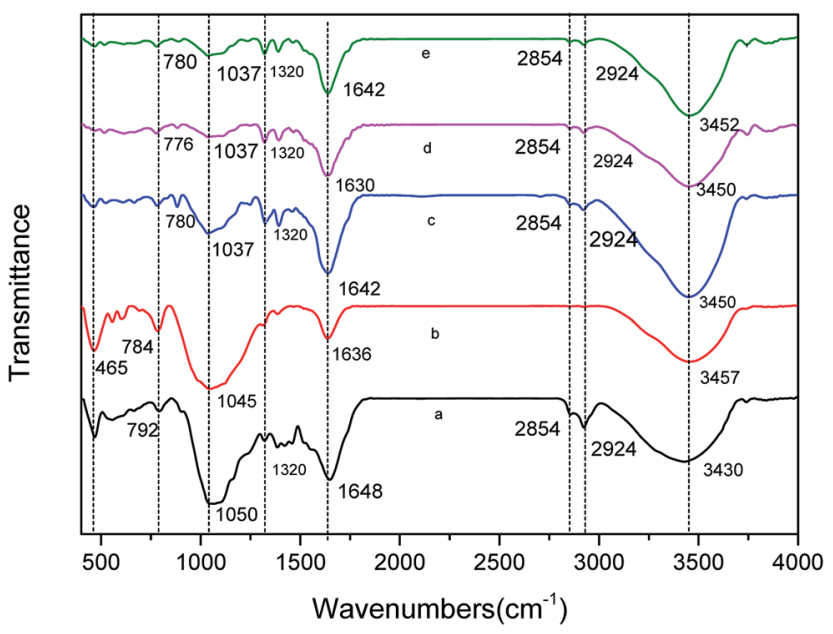

Fig. 1 FTIR of various CMB prepared under different conditions. (a) $\mathrm{CMB}_{200}$; (b) $\mathrm{CMB}_{800}$; (c) $\mathrm{CMB}_{200-80}$; (d) $\mathrm{CMB}_{200-180}$; (e) $\mathrm{CMB}_{200-180-w}$.

which provides another explanation for the good adsorption effectiveness of $\mathrm{CMB}_{200}$.

3.1.2. BET. The pore structures of $\mathrm{CMB}_{200}$ and $\mathrm{CMB}_{800}$ were studied. The specific surface area, pore volume and average pore diameter of $\mathrm{CMB}_{200}$ are $0.3276 \mathrm{~m}^{2} \mathrm{~g}^{-1}, 0.00613 \mathrm{~cm}^{3} \mathrm{~g}^{-1}$ and $75.02 \mathrm{~nm}$, respectively. In contrast, the specific surface area, pore volume and average pore diameter of $\mathrm{CMB}_{800}$ are $3.627 \mathrm{~m}^{2} \mathrm{~g}^{-1}, 0.0107 \mathrm{~cm}^{3} \mathrm{~g}^{-1}$ and $12.979 \mathrm{~nm}$, respectively. Compared with $\mathrm{CMB}_{800}, \mathrm{CMB}_{200}$ has a smaller specific surface area and pore volume and a larger average pore diameter. Meanwhile, $\mathrm{CMB}_{200}$ has more micro-pores smaller than $2 \mathrm{~nm}$ and meso-pores larger than $8 \mathrm{~nm}$. In combination with a previous experimental study of the removal of $\mathrm{MB}$, it is clear that the adsorption of organic contaminants proceeds differently from gas adsorption, due to the much larger molecular size of MB than that of $\mathrm{N}_{2}{ }^{34}$

3.1.3. FTIR. Fig. 1 shows the FTIR spectra for pristine $\mathrm{CMB}_{200}$, pristine $\mathrm{CMB}_{800}$, and $\mathrm{CMB}_{200}$ following the adsorption and desorption of MB. The functional groups corresponding to each spectrum are presented in Table 3. The bands between 3280 and $3647 \mathrm{~cm}^{-1}$ are produced by the hydroxyl stretching vibration of free phenol. ${ }^{35}$ The two bands observed at 2923 and $2854 \mathrm{~cm}^{-1}$ were assigned to asymmetric $\mathrm{C}-\mathrm{H}$ and symmetric $\mathrm{C}-\mathrm{H}$ vibrations, respectively, present in alkyl groups such as $-\mathrm{CH}_{2}$ and $-\mathrm{CH}_{3}{ }^{5,14}$ The bands between 1700 and $1500 \mathrm{~cm}^{-1}$ were attributed to $\mathrm{C}=\mathrm{C}$ symmetrical stretching of pyrone groups and $\mathrm{C}=\mathrm{O}$ stretching of carboxylic groups. ${ }^{35}$ The bands between $1320 \mathrm{~cm}^{-1}$ and $1210 \mathrm{~cm}^{-1}$ were the axial deformation vibrations of the $\mathrm{C}-\mathrm{O}$ bond in phenols. ${ }^{35}$ The bands between $1000 \mathrm{~cm}^{-1}$ and $1300 \mathrm{~cm}^{-1}$ correspond to the angular deformation in the plane of $\mathrm{C}-\mathrm{H}$ bonds of the aromatic rings. ${ }^{35}$ The peak intensity from $779 \mathrm{~cm}^{-1}$ to $795 \mathrm{~cm}^{-1}$ was assigned to $\mathrm{O}-\mathrm{H}$ stretching. ${ }^{36}$ The peak at $465 \mathrm{~cm}^{-1}$ was attributed to the $\mathrm{Si}-\mathrm{O}-\mathrm{Si}$ bending vibration..$^{37}$ The shift, attenuation and disappearance of the peaks under certain conditions can be seen in Fig. 1 and Table 3.

Comparing the FTIR curves of $\mathrm{CMB}_{200}$ before and after adsorption, it can be seen that fatty hydrocarbons and acid functional groups play a major role in adsorption. After adsorption, the peaks at $465 \mathrm{~cm}^{-1}$ and $2800-2931 \mathrm{~cm}^{-1}$ disappeared, and those at $1000-1160 \mathrm{~cm}^{-1}$ decreased. From the above results of Boehm titration, the adsorption ability of the biochar was closely related to the surface functional groups. Comparing the FTIR curves of $\mathrm{CMB}_{200}$ after contact times of $180 \mathrm{~min}$ and $80 \mathrm{~min}$, no significant changes were found in the positions and intensity of the various peaks, and the curves did not change after washing. This implies that the adsorptive role played by the functional groups of $\mathrm{CMB}_{200}$ became less important after $80 \mathrm{~min}$, and the adsorption after this time was dominated by surface physical adsorption.

3.1.4. SEM. Fig. 2 shows the SEM images of CMB prepared at different temperatures and before or after adsorption of MB. The amount of pores on $\mathrm{CMB}_{800}$ is much greater than on $\mathrm{CMB}_{200}$, indicating that the specific surface area of $\mathrm{CMB}$ is increased under a higher pyrolysis temperature. However, the lower adsorption efficiency of $\mathrm{CMB}_{800}$ reveals that the pores on CMB do not play a major role in the process of adsorption. Comparing the SEM images of $\mathrm{CMB}_{200-80}$ and $\mathrm{CMB}_{200-180}$, the latter is smoother and displays no pores, meaning it is close to saturated adsorption. At saturation, adsorption occurs mainly by internal diffusion, and the adsorption rate is slow. $\mathrm{CMB}_{200-180-\mathrm{w}}$ was oven-dried at $105{ }^{\circ} \mathrm{C}$, and used for another round of adsorption of MB under the same conditions. The resulting MB removal rate was $38 \%$. Comparing Fig. $2 \mathrm{~d}$ and e, the amount of pores was increased after washing, indicating that in the later stages adsorption occurred mainly by internal diffusion.

\subsection{Adsorption experiments}

3.2.1. The effect of types of biochar. Temperature of preparation is an important parameter affecting biochar

Table 3 Functional groups of various CMB prepared under different conditions

\begin{tabular}{|c|c|c|c|c|c|}
\hline $\mathrm{CMB}_{200}$ & $\mathrm{CMB}_{800}$ & $\mathrm{CMB}_{200-80}$ & $\mathrm{CMB}_{200-180}$ & $\mathrm{CMB}_{200-180-\mathrm{w}}$ & Functional groups \\
\hline 3430 & 3457 & 3450 & 3450 & 3450 & Free phenols $-\mathrm{OH}^{34}$ \\
\hline 2924 & - & 2924 & 2924 & 2924 & $-\mathrm{CH}_{2}$ groups $^{4,13}$ \\
\hline 2854 & - & 2854 & 2854 & 2854 & $-\mathrm{CH}_{3}$ groups $^{4,13}$ \\
\hline 1648 & 1636 & 1642 & 1630 & 1642 & $\mathrm{C}=\mathrm{C}, \mathrm{C}=\mathrm{O}$ of carboxylic groups ${ }^{34}$ \\
\hline 1320 & 1312 & 1320 & 1320 & 1320 & $\mathrm{C}-\mathrm{O}$ bond in phenols ${ }^{34}$ \\
\hline 1050 & 1050 & 1037 & 1037 & 1037 & $\mathrm{C}-\mathrm{H}$ bonds of the aromatic ring $\mathrm{s}^{34}$ \\
\hline 792 & 784 & 780 & 776 & 780 & $\mathrm{O}-\mathrm{H}^{35}$ \\
\hline 465 & 465 & 465 & - & 465 & $\mathrm{Si}-\mathrm{O}-\mathrm{Si}^{36}$ \\
\hline
\end{tabular}




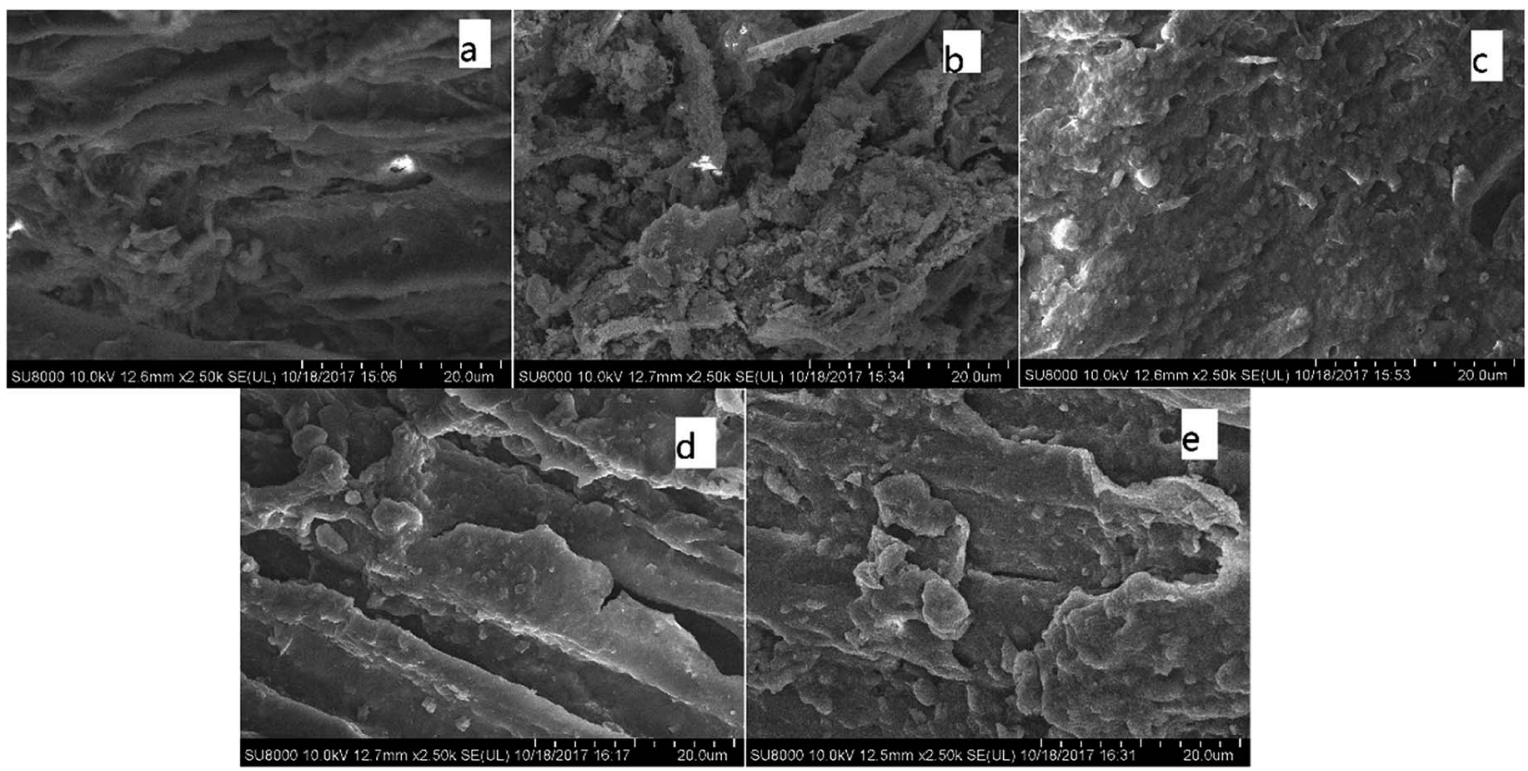

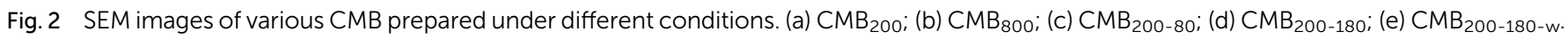

adsorption. ${ }^{38}$ As can be seen from Table 4, the adsorption capacity of $\mathrm{CMB}$ decreased as the pyrolysis temperature was increased from $200{ }^{\circ} \mathrm{C}$ to $800{ }^{\circ} \mathrm{C}$, including a reduction by almost half when going from $200{ }^{\circ} \mathrm{C}$ to $400{ }^{\circ} \mathrm{C}$. As the specific surface area is not the only factor determining the adsorption extent, an increase in surface area would not necessarily lead to an increase of adsorption capacity. For example, with the increase of pyrolysis temperature, the accompanying decrease in surface functional groups may decrease the adsorption capacity. ${ }^{16,39}$ According to Boehm titration and FTIR (which indicated a reduced content of $\mathrm{O}$ and $\mathrm{H}$ at higher temperature), the surface functional groups of the CMB play an important role in the adsorption process. ${ }^{35}$ With the increase of pyrolysis temperature, the ash content of biochar increases, and the soluble alkaline ions formed in water have a great effect on adsorption. ${ }^{22}$ However, when the pyrolysis temperature is further increased, the soluble components in ash undergo crystallization, which impairs the adsorption performance. The sample with the highest soluble ion content was $\mathrm{CMB}_{200} .{ }^{16} \mathrm{In}$ order to compare the adsorption capacity of CMB, various other biochars were prepared under the same conditions (see Section 2.1). The adsorption capacity of $\mathrm{CMB}_{200}$ was better than that of the other studied biomass chars. The hydroxyl groups in

Table 4 The amount of MB adsorbed from solution using different biochars $\left(C_{0}=200 \mathrm{mg} \mathrm{L}^{-1}, W=0.025 \mathrm{~g}, V=20 \mathrm{~mL}, T=25^{\circ} \mathrm{C}, t=80\right.$ $\min$ )

\begin{tabular}{lllr}
\hline Sample & $q_{t}\left(\mathrm{mg} \mathrm{g}^{-1}\right)$ & Sample & \multicolumn{1}{c}{$q_{t}\left(\mathrm{mg} \mathrm{g}^{-1}\right)$} \\
\hline $\mathrm{CMB}_{200}$ & $129.95 \pm 5.44$ & $\mathrm{SDB}_{200}$ & $33.20 \pm 2.89$ \\
$\mathrm{CMB}_{400}$ & $55.10 \pm 2.66$ & $\mathrm{CSB}_{200}$ & $69.37 \pm 3.03$ \\
$\mathrm{CMB}_{600}$ & $55.99 \pm 1.52$ & $\mathrm{RS} B_{200}$ & $102.21 \pm 2.44$ \\
$\mathrm{CMB}_{800}$ & $40.99 \pm 0.85$ & $\mathrm{RS}_{200}$ & $50.03 \pm 0.91$ \\
& & $\mathrm{RCB}_{200}$ & $23.08 \pm 1.91$
\end{tabular}

hemicellulose and cellulose would in principle benefit adsorption, but because of the restrictive effect of the hydrogen-bond network of cellulose molecules, they have low accessibility on the biomass surface. ${ }^{25}$ The cellulose and hemicellulose in CM have been digested by cattle, destroying their original structure. This is why the adsorption performance of CMB is higher than that of the other biochars prepared in low temperature pyrolysis conditions. $^{25}$

3.2.2. CMB with different treatment conditions. CM samples prepared for different times and at different temperatures $\left(200-300{ }^{\circ} \mathrm{C}\right)$ were used for adsorption, and the results are shown in Fig. 3. CMB treated by $200{ }^{\circ} \mathrm{C}$ torrefaction showed the optimal adsorption characteristics. Cao et al. found that the best adsorption of heavy metal ions was achieved by biomass

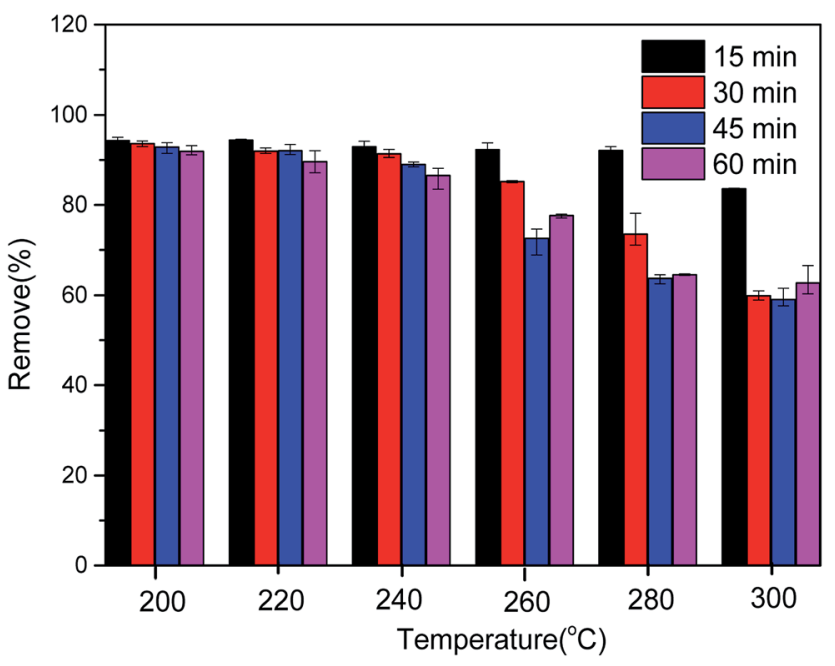

Fig. 3 Effect of torrefaction temperature and torrefaction time of CMB on removal rate. $\left(C_{0}=100 \mathrm{mg} \mathrm{L}^{-1}, W=0.01 \mathrm{~g}, V=20 \mathrm{~mL}, t=\right.$ $80 \min , T=25^{\circ} \mathrm{C}$ ) 

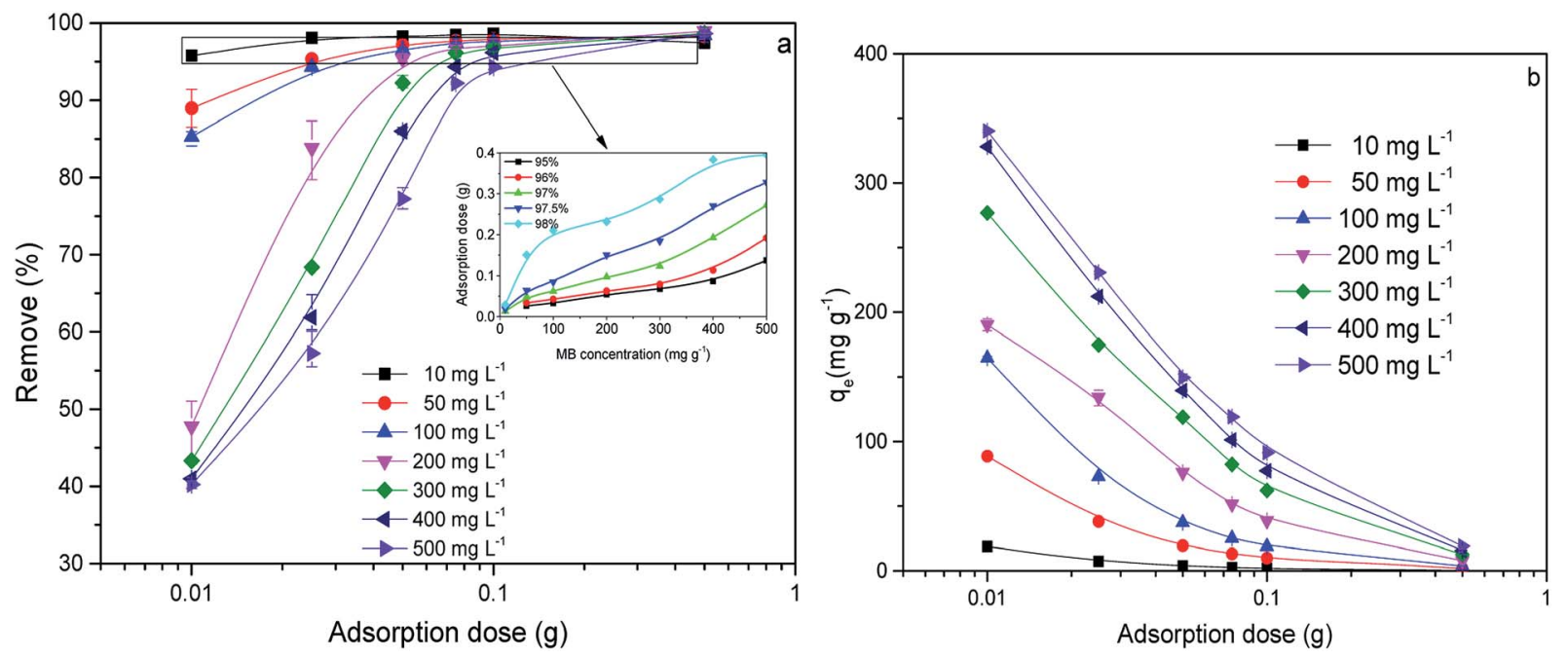

Fig. 4 The effect of different adsorption doses $\left(T=25^{\circ} \mathrm{C}, t=80 \mathrm{~min}\right)$.

char prepared at $350{ }^{\circ} \mathrm{C}^{26}$ In the present study, the adsorption rate decreased with the increase of pyrolysis temperature and pyrolysis time. The pyrolysis of $\mathrm{CM}$ at $200^{\circ} \mathrm{C}$, known as the "L" carbon, usually produces acidic surface oxides, which are negative..$^{40}$ The negative charge on CMB promotes adsorption of $\mathrm{MB}$ via electrostatic interaction with the positive charge on the MB surface, ${ }^{41}$ and the adsorption through interaction between oppositely charged ions is highly favorable.$^{42}$ However, at higher temperature the negative groups were destroyed, leading to a worse adsorption performance. Likewise, with the increase of pyrolysis time, the surface structure of CMB was gradually destroyed, and the acid functional groups decomposed, again leading to a worse adsorption performance. A similar influence of pyrolysis time on biochar adsorption was also found in a previous study. ${ }^{38}$

3.2.3. The effect of adsorbent dose. Fig. 4 shows the effect of adsorbent dose on adsorption. The removal rate of $\mathrm{MB}$ increased from $47.76 \%$ to $98.95 \%$ with increasing the adsorbent dose from $0.01 \mathrm{~g}$ to $0.5 \mathrm{~g}$ at $C_{0}=200 \mathrm{mg} \mathrm{L}^{-1}$, which can be attributed to the increased adsorbent surface area and availability of more adsorption sites. ${ }^{43}$ The decrease of $q_{\mathrm{e}}$ from $190.33 \mathrm{mg} \mathrm{g}^{-1}$ to $7.887 \mathrm{mg} \mathrm{g}^{-1}$ with increasing adsorbent dose from $0.01 \mathrm{~g}$ to $0.5 \mathrm{~g}$ at $C_{0}=200 \mathrm{mg} \mathrm{L}^{-1}$ was due to the competition between adsorption and the separation caused by the concentration gradient. ${ }^{44}$ One reason is that at a fixed concentration and volume of $\mathrm{MB}$, the increase of the adsorbent dose will prevent the saturation of adsorption sites during the adsorption process. ${ }^{45}$ At the same time, the particle aggregation of adsorbent would lead to a reduction in the adsorbent capacity through decreasing the total surface area and increasing the diffusional path length. ${ }^{44,45}$ The removal rate of MB reached $95-98 \%$ at high adsorbent doses, as shown in Fig. 4a. For $\mathrm{MB}$ at a concentration of $500 \mathrm{mg} \mathrm{L}^{-1}$, the removal rate of $95 \%$ was achieved with an adsorbent dose of only $0.1 \mathrm{~g}$ $\mathrm{CMB}_{200}$. At this concentration of $\mathrm{MB}$, a dose of $0.4 \mathrm{~g} \mathrm{CMB} \mathrm{CMo}_{20}$ was needed to reach a $98 \%$ removal rate. In conclusion, $\mathrm{CMB}_{200}$ has obvious advantages for $\mathrm{MB}$ removal due to the pretreatment procedure. However, to enhance the removal rate above $95 \%$ requires uneconomically high adsorbent doses.

3.2.4. The effect of initial MB concentration. Fig. 5 shows the relationship between the adsorption capacity and the initial MB concentration. The fast sorption at the initial stage may be due to the large number of active sites available on the CMB. ${ }^{8}$ After rapid diffusion of MB molecules from the bulk solution to the exterior surface of adsorbent particles, the removal rate gradually slowed down until reaching equilibrium. This may be a consequence of the saturation of active sites on the exterior surface and the penetration of MB molecules into the pores of the adsorbent. ${ }^{46}$ When the MB concentration was increased from $10 \mathrm{mg} \mathrm{L}^{-1}$ to $500 \mathrm{mg} \mathrm{L}^{-1}$ with an adsorbent dose of $0.025 \mathrm{~g}$ $\mathrm{CMB}$, the equilibrium adsorption capacity increased from $7.55 \mathrm{mg} \mathrm{g}^{-1}$ to $241.99 \mathrm{mg} \mathrm{g}^{-1}$. Increasing the initial concentration of MB provides an important driving force to overcome the mass transfer resistance between the aqueous and the solid phase, ${ }^{31}$ and the interaction between $\mathrm{MB}$ and adsorbent is enhanced, resulting in higher adsorption capacity.

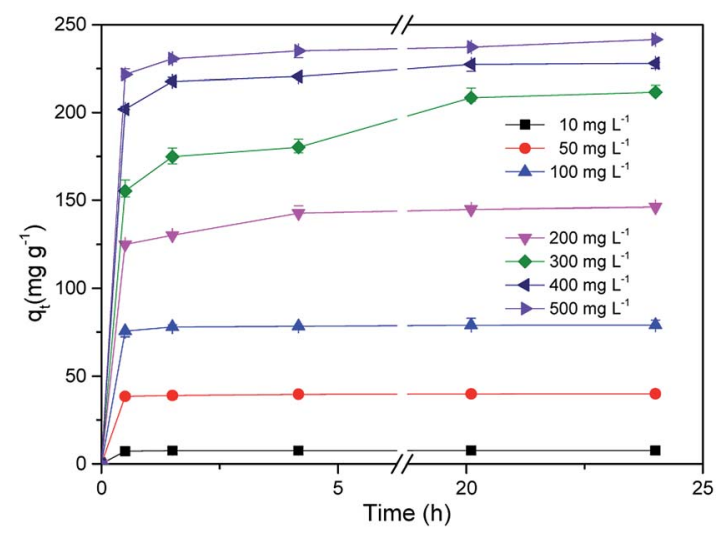

Fig. 5 The effect of contact time on the adsorption capacity at different initial $\mathrm{MB}$ concentrations $\left(W=0.025 \mathrm{~g}, V=20 \mathrm{~mL}, T=25^{\circ} \mathrm{C}\right)$. 


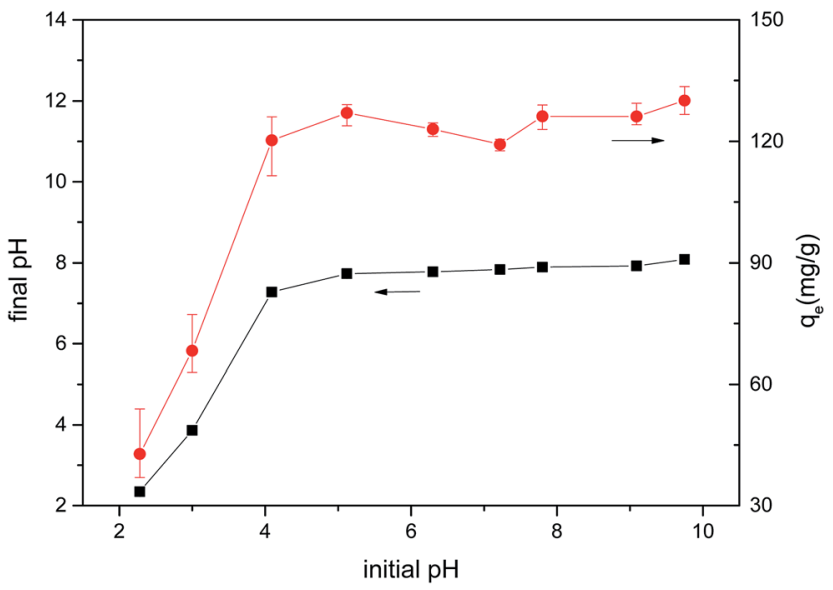

Fig. 6 The effect of initial $\mathrm{pH}$ value on the adsorption of MB by CMB $\left(W=0.025 \mathrm{~g}, T=25^{\circ} \mathrm{C}, t=80 \mathrm{~min}, V=20 \mathrm{~mL}\right)$.

3.2.5. The effect of $\mathbf{p H}$. The $\mathrm{pH}$ of the solution is an important parameter for adsorption. The $\mathrm{pH}$ of the solution not only affects the surface charge of the adsorbent, but also influences the separation of functional groups on the active site of the adsorbent and affects the structure of the MB. ${ }^{47}$ The surface charge distribution of CM depends on the type of surface functional groups and the $\mathrm{pH}$ of the solution. ${ }^{29}$ Fig. 6 shows the effect of initial $\mathrm{pH}$ on adsorption. With the increase of solution $\mathrm{pH}$, the $\mathrm{MB}$ adsorption capacity tends to increase on the whole. The adsorption efficiency in alkaline conditions was obviously higher than that in acidic conditions. The largest increase in the rate of the adsorption efficiency was observed when changing the $\mathrm{pH}$ from 3 to 4 . Because $\mathrm{CMB}_{200}$ is alkaline, the $\mathrm{pH}$ of the solution after adsorption is alkaline. ${ }^{16}$ The negative charge is separated from the oxygen-containing functional group of biochar, making the negative charge on biochar are more negative. As the $\mathrm{pH}$ of the solution increases, the potential becomes progressively more negative, and the electrostatic effect becomes more pronounced. ${ }^{22}$ At $\mathrm{pH}>\mathrm{pH}_{\mathrm{IEP}}$, because of the deprotonation of carboxyl groups and phenol hydroxyl groups, the biochar surface is negatively charged..$^{32}$ Therefore, electrostatic attraction occurs between the functional groups on the surface of the biochar and the positively charged $\mathrm{MB}$ ions in the alkaline solution. Conversely, at $\mathrm{pH}<\mathrm{pH}_{\mathrm{IEP}}$, the surface of biochar has a positive charge, and experiences electrostatic repulsion from the positive $\mathrm{MB}$ ions. ${ }^{32}$ In an acidic environment, there exists a competition for adsorption between $\mathrm{H}^{+}$and MB cations, and the MB adsorption efficiency decreases. However, the remarkably high $q_{\mathrm{e}}$ at $\mathrm{pH}<\mathrm{pH}_{\mathrm{IEP}}$, under which conditions most of the binding sites are protonated, suggests that hydrophobic interactions also contributed to MB removal.

3.2.6. The effect of temperature. As can be seen from Fig. 7, with increasing contact time, the adsorption capacity increased at all temperatures. At $5{ }^{\circ} \mathrm{C}$, the adsorption capacity increased rapidly throughout the whole period of 0-360 min. However, at 15,25 and $35{ }^{\circ} \mathrm{C}$, the main increase of adsorption occurred in the first $30 \mathrm{~min}$. At any given adsorption time, the adsorption capacity was greater at higher temperatures within the range from $5{ }^{\circ} \mathrm{C}$ to $25^{\circ} \mathrm{C}$, in accordance with the literature. ${ }^{4}$ The effect

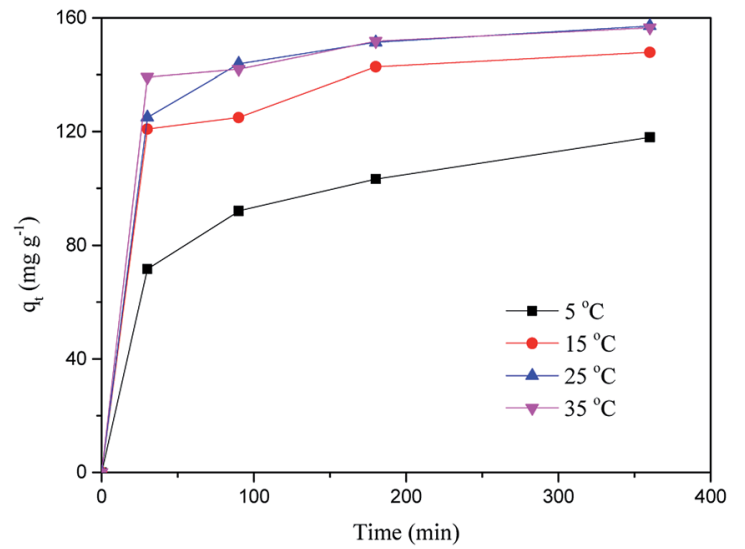

Fig. 7 The effect of contact time on the adsorption capacity at different temperatures $(W=0.025 \mathrm{~g}, V=20 \mathrm{~mL}$ ).

of temperature on the adsorption capacity was smaller in the temperature range from $25{ }^{\circ} \mathrm{C}$ to $35^{\circ} \mathrm{C}$, implying that $\mathrm{CMB}$ can be used for wastewater treatment at ambient temperature.

\subsection{Adsorption isotherm}

To model the adsorption process of MB solution onto biochar, the adsorption data were fitted using the Langmuir, Freundlich and Temkin isotherm models. The Langmuir, Freundlich, and Temkin isothermal equations are as follows. ${ }^{\mathbf{4 8 , 4 9}}$

$$
\begin{gathered}
\frac{C_{\mathrm{e}}}{q_{\mathrm{e}}}=\frac{1}{Q_{0} b}+\frac{1}{Q_{0}} C_{\mathrm{e}} \\
\ln \left(q_{\mathrm{e}}\right)=\frac{1}{n} \ln \left(C_{\mathrm{e}}\right)+\ln \left(K_{\mathrm{F}}\right) \\
q_{\mathrm{e}}=\frac{R T}{b_{\mathrm{T}}} \ln \left(K_{\mathrm{T}}\right)+\frac{R T}{b_{\mathrm{T}}} \ln \left(C_{\mathrm{e}}\right)
\end{gathered}
$$

In eqn (4)-(6), $C_{\mathrm{e}}$ is the equilibrium concentration $\left(\mathrm{mg} \mathrm{L}^{-1}\right)$; $q_{\mathrm{e}}$ is the adsorption capacity at equilibrium time $\left(\mathrm{mg} \mathrm{g}^{-1}\right) ; Q_{0}$ is the maximum adsorption capacity $\left(\mathrm{mg} \mathrm{g}^{-1}\right) ; b$ is the Langmuir constant related to adsorption capacity $\left(\mathrm{mg} \mathrm{g}^{-1}\right) ; K_{\mathrm{F}}$ is the Freundlich constant $\left(\mathrm{L} \mathrm{mg}^{-1}\right) ; n$ is the adsorption "intensity"; $K_{\mathrm{T}}$ is the equilibrium binding constant $\left(\mathrm{L} \mathrm{mg}^{-1}\right) ; b_{\mathrm{T}}$ is the Temkin isotherm constant.

The adsorption isotherm curves of CMB at different temperatures and different $\mathrm{MB}$ concentrations are given in Fig. 8. The fitting parameters of the adsorption isothermal models and the correlation coefficients of the experimental data are given in Table 5 .

First of all, the correlation coefficients indicate that the Langmuir model is better than the Freundlich model, which means the adsorption process is a single layer adsorption process. $^{50}$ The factor $1 / n$ in the Freundlich isotherm model reflects the heterogeneity factor and the adsorption intensity; the smaller the $1 / n$, the greater the expected heterogeneity. ${ }^{51}$ The Temkin isotherm model, which describes adsorption as a chemical process, assumes that the heat of adsorption of all 

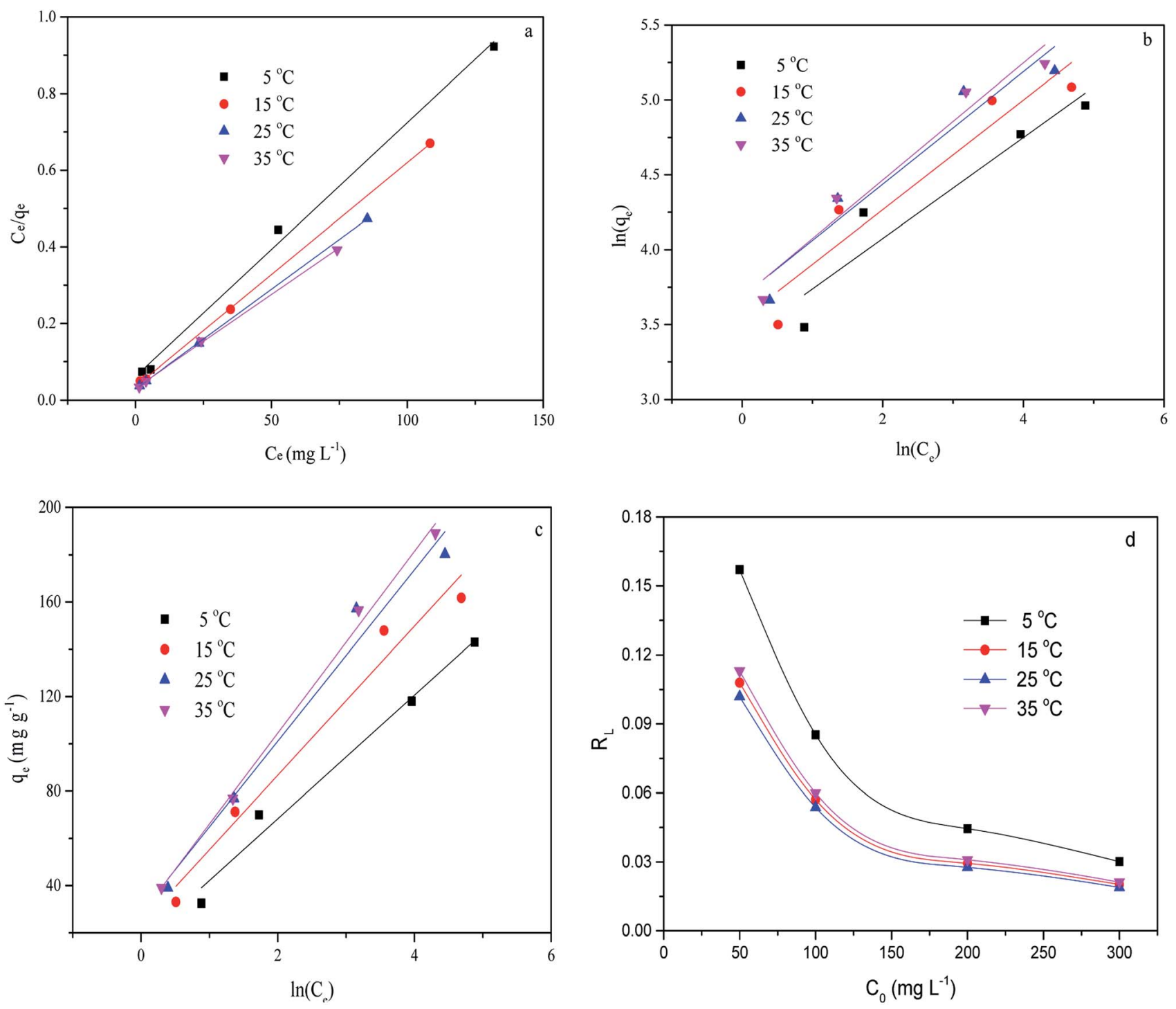

Fig. 8 Linear fits of the adsorption of MB on CMB predicted by various isotherm models. (a) Langmuir; (b) Freundlich; (c) Temkin; (d) $R_{\mathrm{L}}$.

the molecules on a layer decreases linearly rather than logarithmically with coverage..$^{48}$ In the present study, the Temkin isotherm fitted the results well $\left(R^{2}>0.96\right)$. Therefore, electrostatic interaction is an important mechanism for the adsorption of $\mathrm{MB}$ on $\mathrm{CMB}$.

A separation or equilibrium factor $\left(R_{\mathrm{L}}\right)$ can be defined based on the Langmuir isotherm such that $R_{\mathrm{L}}=1 /\left(1+C_{0} b\right)$, where $C_{0}$ is the initial $\mathrm{MB}$ concentration. When $0<R_{\mathrm{L}}<1$ this indicates favorable adsorption, and $R_{\mathrm{L}}>1$ means unfavorable adsorption; $R_{\mathrm{L}}=0$ indicates irreversible adsorption, and $R_{\mathrm{L}}=1$ means linear adsorption. ${ }^{46}$ In the present study, as shown in Fig. 8, $R_{\mathrm{L}}$ was less than 1 , which indicated that the adsorption of $\mathrm{MB}$ on $\mathrm{CMB}_{200}$ was favorable. Furthermore, increasing the initial MB concentration enhanced the adsorption process. With the increase of temperature, the decreased $R_{\mathrm{L}}$ implied the favorable adsorption of MB onto CMB.

Table 5 Adsorption isotherm parameters of $\mathrm{MB}$ on $\mathrm{CMB}_{200}$ for various isotherm models

\begin{tabular}{|c|c|c|c|c|c|c|c|c|c|}
\hline$T\left({ }^{\circ} \mathrm{C}\right)$ & \multicolumn{3}{|c|}{ Langmuir model } & \multicolumn{3}{|c|}{ Freundlich model } & \multicolumn{3}{|l|}{ Temkin } \\
\hline 15 & 170.94 & 0.1653 & 0.9997 & 34.33 & 0.3657 & 0.8593 & 2.11 & 74.63 & 0.9601 \\
\hline 25 & 192.31 & 0.1763 & 0.9999 & 39.91 & 0.3756 & 0.8887 & 2.20 & 68.38 & 0.9646 \\
\hline 35 & 204.08 & 0.1184 & 0.9989 & 39.77 & 0.3911 & 0.9352 & 2.05 & 66.63 & 0.9933 \\
\hline
\end{tabular}




\subsection{Adsorption kinetics}

The adsorption kinetics contain information about the physical or chemical interaction between adsorbent and adsorbate, and are important for evaluating the mechanism and efficiency of the sorption process. ${ }^{46}$ In order to study the mechanism of MB adsorption on CMB, pseudo-first order, pseudo-second order, and intra-particle diffusion models were separately used to describe the kinetic process. ${ }^{51,52}$

$$
\begin{gathered}
\log \left(q_{\mathrm{e}}-q_{t}\right)=\log q_{\mathrm{e}}-\frac{k_{1}}{2.303} t \\
\frac{t}{q_{t}}=\frac{1}{k_{2} q_{\mathrm{e}}^{2}}+\frac{1}{q_{\mathrm{e}}} t
\end{gathered}
$$

$$
q_{t}=k_{\mathrm{d}} \times t^{\frac{1}{2}}+C
$$

In eqn (7)-(9), $q_{\mathrm{e}}$ is the adsorption capacity at equilibrium time $\left(\mathrm{mg} \mathrm{g}^{-1}\right) ; q_{t}$ is the adsorption capacity at time $t\left(\mathrm{mg} \mathrm{g}^{-1}\right) ; k_{1}$ is the pseudo-first order rate constant $\left(\mathrm{min}^{-1}\right) ; k_{2}$ is the pseudosecond order rate constant $\left(\mathrm{g} \mathrm{mg}^{-1} \mathrm{~min}^{-1}\right) ; k_{\mathrm{d}}$ is the intraparticle diffusion rate constant $\left(\mathrm{g} \mathrm{mg}^{-1} \mathrm{~min}^{-1 / 2}\right) ; C$ is a constant.

Fig. 9 shows the adsorption kinetic curve of $\mathrm{MB}$ in solution onto $\mathrm{CMB}$ at $25{ }^{\circ} \mathrm{C}$. Table 6 gives the fitting parameters of the three kinetic models of the adsorption process under different temperature and $\mathrm{MB}$ concentration conditions.
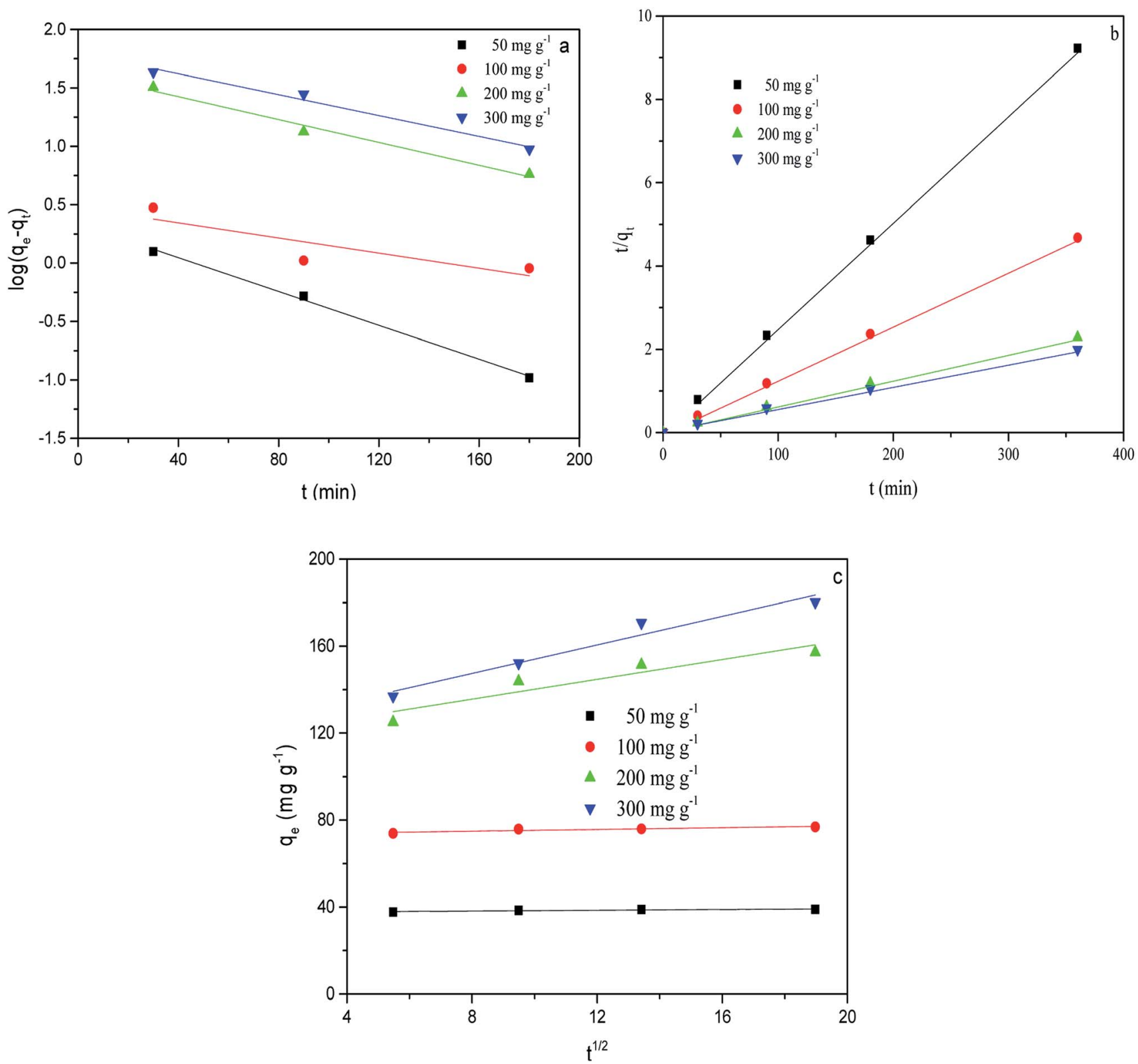

Fig. 9 Kinetic fits for MB adsorption on $\mathrm{CMB}\left(25^{\circ} \mathrm{C}\right)$ using different kinetic models. (a) Pseudo-first order; (b) pseudo-second order; (c) intraparticle diffusion. 
Table 6 Adsorption kinetic parameters of $\mathrm{MB}$ on $\mathrm{CMB}_{200}$

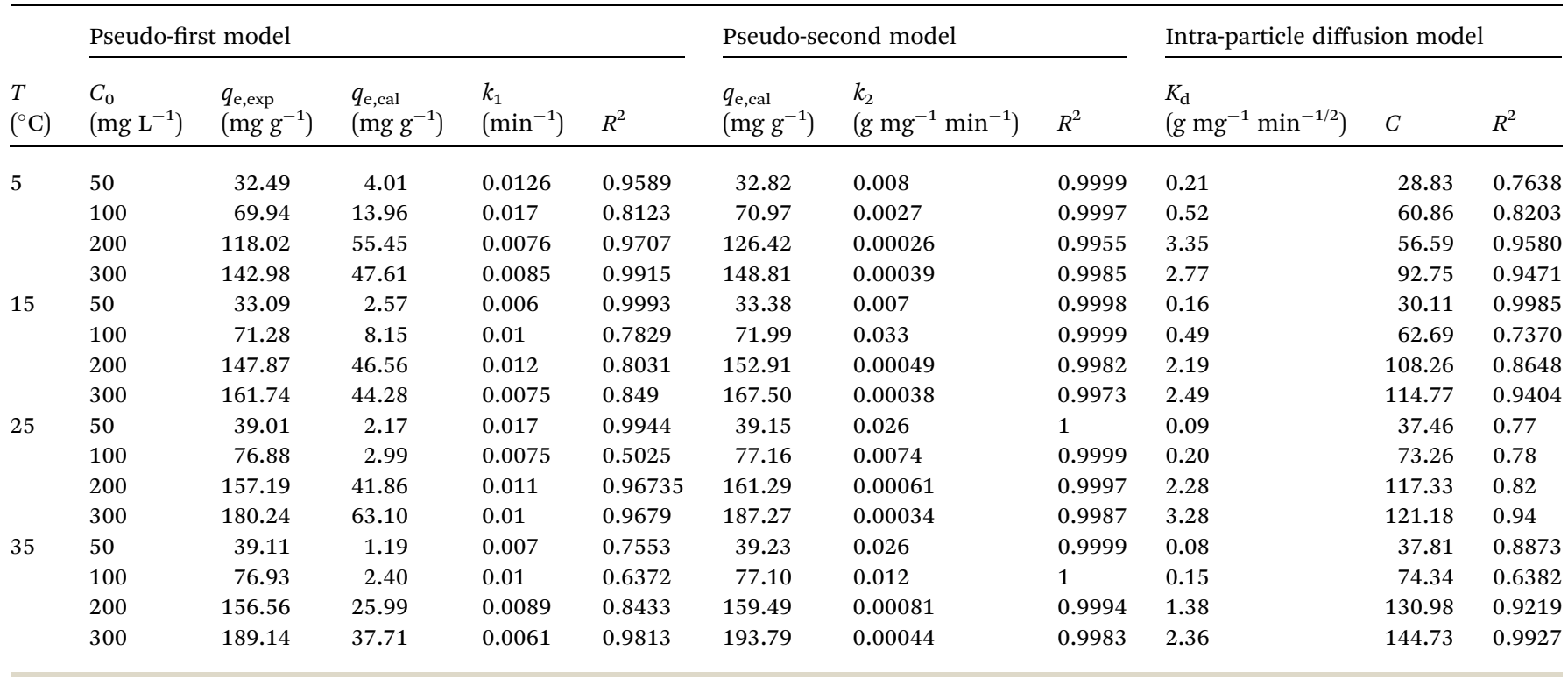

At $25{ }^{\circ} \mathrm{C}$, the pseudo-second order model $\left(R^{2}>0.99\right)$ better describes the adsorption kinetics than the pseudo-first order model. The pseudo-second order model is valid in the case of diffusion of the external liquid membrane, surface adsorption and intra-particle diffusion; this implies that the adsorption process is controlled by chemical adsorption, involving exchange or sharing of electrons between the MB cations and functional groups of the biomass surface..$^{29}$

The intra-particle diffusion model was used to study the mechanisms of adsorption and rate control. ${ }^{49}$ Because $C \neq 0$, the adsorption process may involve various adsorption mechanisms. ${ }^{49}$ The first linear part of the curve represents the surface adsorption, whereas the second linear portion is the slow diffusion of the adsorbate from the surface to the inner holes. ${ }^{47}$ It can be seen that the surface adsorption is fast and is the main step in low concentrations of MB solution. As the concentration of solution increases, the surface adsorption and intra-particle diffusion become more important in the mechanism of $\mathrm{CMB}_{200}$ adsorption.

\subsection{Adsorption thermodynamics}

The thermodynamic parameters of free energy change $\left(\Delta G^{0}, \mathrm{~kJ} \mathrm{~mol}{ }^{-1}\right)$, enthalpy change $\left(\Delta H^{0}, \mathrm{~kJ} \mathrm{~mol}^{-1}\right)$ and entropy change $\left(\Delta S^{0}, \mathrm{~kJ} \mathrm{~mol}^{-1} \mathrm{~K}^{-1}\right)$ were used to describe the

Table 7 Thermodynamic parameters of $\mathrm{MB}$ adsorption on $\mathrm{CMB}_{200}$

\begin{tabular}{llll}
\hline $\begin{array}{l}\text { Temperature } \\
(\mathrm{K})\end{array}$ & $\begin{array}{l}\Delta G \\
\left.(\mathrm{~kJ} \mathrm{~mol})^{-1}\right)\end{array}$ & $\begin{array}{l}\Delta H \\
\left(\mathrm{~kJ} \mathrm{~mol}^{-1}\right)\end{array}$ & $\begin{array}{l}\Delta S \\
\left(\mathrm{~J} \mathrm{~mol}^{-1} \mathrm{~K}^{-1}\right)\end{array}$ \\
\hline 278 & -6.439 & -16.169 & 82.493 \\
288 & -8.004 & & \\
298 & -8.734 & & \\
308 & -8.881 & &
\end{tabular}

thermodynamic behavior of the adsorption of $\mathrm{MB}$ on $\mathrm{CMB}_{200}$. These parameters were estimated using the following equations: ${ }^{52}$

$$
\begin{aligned}
& \Delta G=-R T \ln (K) \\
& \ln (K)=\frac{\Delta S}{R}+\frac{\Delta H}{R} \frac{1}{T}
\end{aligned}
$$

where $R$ is the universal gas constant $\left(8.314 \mathrm{~J} \mathrm{~mol}^{-1} \mathrm{~K}^{-1}\right) ; T$ is the temperature, $\mathrm{K} ; \Delta H$ is the adsorption enthalpy, $\mathrm{kJ} \mathrm{mol}^{-1} ; \Delta S$ is the adsorption entropy, $\mathrm{J} \mathrm{mol}^{-1} \mathrm{~K}^{-1} ; K$ is the thermodynamic equilibrium constant, which equals $Q_{0} \times b$ (parameters of the Langmuir isotherm).

The thermodynamic parameters of the adsorption of $\mathrm{MB}$ are shown in Table 7 . The negative $\Delta H$ and the positive $\Delta G$ show that the adsorption process is spontaneous and exothermic. ${ }^{52}$ Hence, as the adsorption temperature increases, the adsorption capacity increases. The $\Delta G$ values of MB adsorption onto biochar were measured at $278 \mathrm{~K}, 288 \mathrm{~K}, 298 \mathrm{~K}$ and $308 \mathrm{~K} . \Delta G$ decreases with the increase of temperature, indicating that adsorption is more favorable at higher temperature. ${ }^{14}$ The high value of $\Delta H$ indicated a strong interaction between the adsorbate and adsorbent. ${ }^{53}$ Meanwhile, the positive values of $\Delta S$ suggest increased randomness at the solid/solution interface during the adsorption process. ${ }^{52}$

Table 8 The $M B$ removal rate of $\mathrm{CMB}_{200}$ after different treatments $\left(C_{0}\right.$ $=100 \mathrm{mg} \mathrm{L}^{-1}, W=0.025 \mathrm{~g}, T=25^{\circ} \mathrm{C}, t=80 \mathrm{~min}$ )

\begin{tabular}{ll} 
Adsorbent & Removal rate (\%) \\
\hline $\mathrm{CMB}_{200}$ & $93.61 \pm 2.25$ \\
$\mathrm{CMB}_{200}+$ wash ash & $20.35 \pm 1.82$ \\
$\mathrm{CMB}_{200}+$ esterification & $54.80 \pm 0.32$
\end{tabular}


Table 9 The release of cations during MB adsorption by $\mathrm{CMB}_{200}$ at 25 ${ }^{\circ} \mathrm{C}$

\begin{tabular}{lllllll}
\hline & \multicolumn{4}{l}{ The net of released cations $\left(\mathrm{mol} \mathrm{kg}^{-1}\right)$} & \\
\cline { 2 - 5 } Sample & $\mathrm{Ca}^{2+}$ & $\mathrm{Mg}^{2+}$ & $\mathrm{Na}^{+}$ & $\mathrm{K}^{+}$ & Total & $\mathrm{MB}\left(\mathrm{mol} \mathrm{kg}^{-1}\right)$ \\
\hline $\mathrm{CMB}_{200}$ & 0.088 & 0.206 & 0.0008 & 0.00181 & 0.20861 & 0.38544
\end{tabular}

\subsection{Possible mechanisms}

As the temperature of pyrolysis increases, the pores become larger, but the adsorption capacity decreases. This phenomenon indicates that in the process of adsorption by $\mathrm{CMB}$, the pores do not play a major role. The same conclusion was reached in a study of the adsorption of Cr by coconut shells. ${ }^{25}$ As the temperature of pyrolysis increases, the trend of adsorption capacity is the same as that of the amount of functional groups, indicating that adsorption is related to oxygen-containing functional groups. ${ }^{14}$

From the FTIR, as the pyrolysis temperature increased, the carboxylic peak weakened and shifted, and the adsorption capacity fell from $129.95 \mathrm{mg} \mathrm{g}^{-1}\left(\mathrm{CMB}_{200}\right)$ to $40.99 \mathrm{mg} \mathrm{g}^{-1}$ $\left(\mathrm{CMB}_{800}\right)$. Combined with the results of Boehm titration, this implies that carboxyl plays an important role in the process of adsorption. In order to further determine the effect of carboxyl groups, methanol was used to treat $\mathrm{CM}$, and the adsorption results using the modified $\mathrm{CM}$ are given in Table 8. The adsorption efficiency decreased from $93.61 \%$ to $54.80 \%$, confirming the important influence of carboxyl groups on the adsorption ability of $\mathrm{CMB}_{200}$.
A possible mechanism of action of carboxyl is as follows. In neutral and alkaline conditions, carboxyl groups release protons, becoming negatively charged, leading to strong electrostatic attraction between carboxyl and $\mathrm{MB}$ cations. ${ }^{47}$ The oxygen-containing functional groups $(-\mathrm{OH})$ of $\mathrm{CMB}_{200}$ are also electrostatically attracted to $\mathrm{MB}$, leading to its removal. ${ }^{54}$

In addition, the oxygen containing functional groups $(-\mathrm{COOH},-\mathrm{OH})$ of $\mathrm{CMB}$ take part in hydrogen bonding with MB. This is one of the reasons for the decreasing adsorption of $\mathrm{MB}$ with increasing pyrolysis temperature: the CMB surface becomes more hydrophobic, and the adsorption capacity of polar molecules like MB is greatly diminished. ${ }^{35,37}$

The $\mathrm{Si}-\mathrm{O}-\mathrm{Si}$ peak at $465 \mathrm{~cm}^{-1}$ is weakened during the adsorption of $\mathrm{MB}$ on $\mathrm{CMB}_{200}$, which suggests that $\mathrm{Si}-\mathrm{O}-\mathrm{Si}$ plays a role in the process of adsorption. Studies in the literature report that $\mathrm{n}-\pi$ interaction occurs between $\mathrm{Si}-\mathrm{O}-\mathrm{Si}$ and $\mathrm{MB}^{48}$ Moreover, in alkaline solution, the presence of $\mathrm{Si}-\mathrm{O}-\mathrm{Si}$ is beneficial to the adsorption of cationic $\mathrm{MB}^{37}$

The $\mathrm{pH}$ change of the solution after the adsorption of CM was observed, and the $\mathrm{pH}$ of the solution decreased under alkaline conditions after adsorption. Considering the results of Boehm titration and FTIR, this may be because of the ionexchange interaction between $\mathrm{MB}$ and $\mathrm{CMB}\left(\mathrm{H}^{+}\right.$ions are liberated, causing the $\mathrm{pH}$ to decrease). ${ }^{23,55}$

In order to determine whether other cationic exchange processes in addition to that of $\mathrm{H}^{+}$ions play a role in $\mathrm{MB}$ adsorption, the net content of cationic exchange was measured, as shown in Table 9. After adsorption, the cationic content in the solution increased, indicating that cationic exchange plays an important role in the process of $\mathrm{MB}$ adsorption. Cation

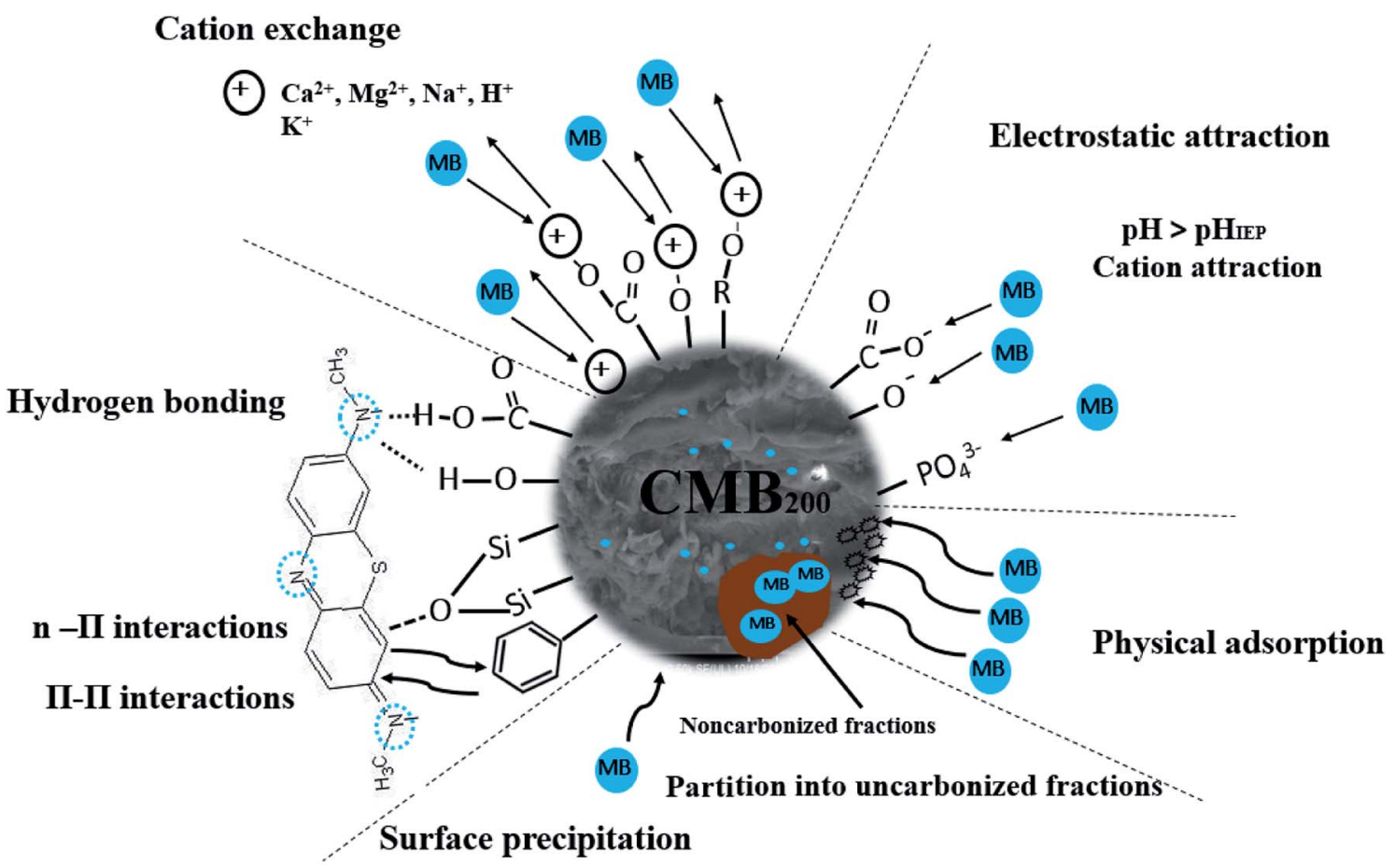

Others

Fig. 10 Interaction mechanisms in the biochar-MB system. 
exchange has been shown previously to play an important role in the adsorption process. ${ }^{29}$ The total amount of cationic release was not equal to the amount of $\mathrm{MB}$ adsorbed. This result indicates that cation exchange is not the only mechanism for the adsorption of $\mathrm{MB}$, and other mechanisms affect the adsorption process.

In order to determine the effect of ash on adsorption, CMB was used to adsorb MB after deashing. The adsorption efficiency of $\mathrm{CMB}$ decreased from $93.61 \%$ to $20.35 \%$, indicating that the ash content plays a very important role in the adsorption process. The ash content mostly contributes to adsorption by the following two mechanisms: (1) the existence of ash means that the CMB surface carries a more negative charge $\left(\mathrm{PO}_{4}{ }^{3-}\right.$ and negatively charged silane groups) in alkaline solution, ${ }^{33}$ leading to a strong electrostatic attraction to $\mathrm{MB}^{\mathbf{2}^{22}}$ (2) cation exchange is closely related to the soluble alkali salts in ash. ${ }^{23}$ The CMB adsorption efficiency decreases as the pyrolysis temperature increases, and is minimized at $300{ }^{\circ} \mathrm{C}$ (within the range $200-300{ }^{\circ} \mathrm{C}$ ). This is because as the temperature rises, the inorganic salts in ash form $\mathrm{P}-\mathrm{Ca}-\mathrm{Mg}$ crystals, ${ }^{21}$ resulting in reduced ash content in the solution, and reduced electrostatic interaction and ion exchange. The possible mechanisms of the MB adsorption process are summarized in Fig. 10.

\section{Conclusion}

The removal of MB from aqueous solution by CMB was studied in this paper. The biochar prepared by low temperature pyrolysis $\left(\mathrm{CMB}_{200}\right)$ has a good ability to adsorb $\mathrm{MB}$, and its removal rate is more than three times that of $\mathrm{CMB}_{800}$. When the initial MB concentration $C_{0}$ is $200 \mathrm{mg} \mathrm{L}^{-1}$ and the $\mathrm{CMB}_{200}$ mass is $0.05 \mathrm{~g}$, the removal rate reaches $95.36 \%$. It is not economically feasible to achieve a removal rate of MB above 95\% using CMB. However, this is an acceptable removal rate of $\mathrm{MB}$ from aqueous solution. The Langmuir and pseudo second order equations can accurately describe the adsorption process. CMB behaves as an adsorbent by single layer adsorption, and increasing the temperature and increasing the initial concentration are conducive to the adsorption process. Thermodynamically the adsorption process is spontaneous and exothermic. The interaction between $\mathrm{CMB}_{200}$ and $\mathrm{MB}$ involves ion exchange, electrostatic attraction, hydrogen bonding and physical adsorption. The high contents of ash and surface functional groups in CM are responsible for its good adsorption performance.

\section{Conflicts of interest}

There are no conflicts to declare.

\section{Acknowledgements}

This research was financially supported by the Natural Science Foundation of Hubei Provincial (2017CFB231), the Special Fund for Agro-scientific Research in the Public Interest of China (201303091) and the Fundamental Research Funds for the Central Universities (2662015QD048, 2015PY077, 201810504073 and 2018230). The authors would like to thank Dr Ruili Gao from HZAU and Dr Honghong Lv from NKU for the experiments help and valuable inputs. The authors also acknowledge the extended help from the Analytical and Testing Center of Huazhong Agricultural University (HZAU).

\section{References}

1 M. Rafatullah, O. Sulaiman, R. Hashim and A. Ahmad, J. Hazard. Mater., 2010, 177, 70-80.

2 O. S. Bello, K. A. Adegoke, A. A. Olaniyan and H. Abdulazeez, Desalin. Water Treat., 2015, 53, 1292-1315.

3 B. H. Hameed, A. T. M. Din and A. L. Ahmad, J. Hazard. Mater., 2007, 141, 819-825.

4 Y. Bulut and H. Aydın, Desalination, 2006, 194, 259-267.

5 K. Mahmoudi, K. Hosni, N. Hamdi and E. Srasra, Korean J. Chem. Eng., 2015, 32, 274-283.

6 D. Pathania, S. Sharma and P. Singh, Arabian J. Chem., 2013, 10, S1445-S1451.

7 S. Altenor, B. Carene, E. Emmanuel, J. Lambert, J. Ehrhardt and S. Gaspard, J. Hazard. Mater., 2009, 165, 1029-1039.

8 M. Ghaedi, A. G. Nasab, S. Khodadoust, M. Rajabi and S. Azizian, J. Ind. Eng. Chem., 2014, 20, 2317-2324.

9 L. Lonappan, T. Rouissi, R. K. Das, S. K. Brar, A. A. Ramirez, M. Verma, R. Y. Surampalli and J. R. Valero, Waste Manag., 2016, 49, 537-544.

10 Q. Qian, M. Machida, M. Aikawa and H. Tatsumoto, J. Mater. Cycles Waste Manage., 2008, 10, 53.

11 Q. Qian, S. Sunohara, Y. Kato, M. A. A. Zaini, M. Machida and H. Tatsumoto, Appl. Surf. Sci., 2008, 254, 4868-4874.

12 S. e. Fang, D. C. W. Tsang, F. Zhou, W. Zhang and R. Qiu, Chemosphere, 2016, 149, 263-271.

13 Q. Miao, Y. Tang, J. Xu, X. Liu, L. Xiao and Q. Chen, J. Taiwan Inst. Chem. Eng., 2013, 44, 458-465.

14 L. Leng, X. Yuan, H. Huang, J. Shao, H. Wang, X. Chen and G. Zeng, Appl. Surf. Sci., 2015, 346, 223-231.

15 H. Cao, Y. Xin, D. Wang and Q. Yuan, Bioresour. Technol., 2014, 172, 219-225.

16 X. Cao and W. Harris, Bioresour. Technol., 2010, 101, 52225228.

17 K. B. Cantrell, P. G. Hunt, M. Uchimiya, J. M. Novak and K. S. Ro, Bioresour. Technol., 2012, 107, 419.

18 N. A. Qambrani, M. M. Rahman, S. Won, S. Shim and C. Ra, Renewable Sustainable Energy Rev., 2017, 79, 255-273.

19 X. Xu, X. Cao and L. Zhao, Chemosphere, 2013, 92, 955-961. 20 Y. Amano, Desalin. Water Treat., 2014, 52, 6420-6429.

21 X. Xu, X. Cao, L. Zhao, H. Wang, H. Yu and B. Gao, Environ. Sci. Pollut. Res., 2013, 20, 358-368.

22 R. K. Xu, S. C. Xiao, J. H. Yuan and A. Z. Zhao, Bioresour. Technol., 2011, 102, 10293-10298.

23 P. Janos, S. Coskun, V. Pilarova and J. Rejnek, Bioresour. Technol., 2009, 100, 1450-1453.

24 W. Ding, X. Dong, I. M. Ime, B. Gao and L. Q. Ma, Chemosphere, 2014, 105, 68-74.

25 Y.-S. Shen, S.-L. Wang, Y.-M. Tzou, Y.-Y. Yan and W.-H. Kuan, Bioresour. Technol., 2012, 104, 165-172.

26 X. D. Cao, L. Ma, B. Gao and W. Harris, Environ. Sci. Technol., 2009, 43, 3285-3291. 
27 H. Lu, W. Zhang, S. Wang, L. Zhuang, Y. Yang and R. Qiu, J. Anal. Appl. Pyrolysis, 2013, 102, 137-143.

28 B. Yi, Q. Yuan, H. Cao, W. Niu, M. Wang, Y. Zhu and S. Yan, RSC Adv., 2018, 8, 11705-11713.

29 D. Mitrogiannis, G. Markou, A. Çelekli and H. Bozkurt, J. Environ. Chem. Eng., 2015, 3, 670-680.

30 Z. Yuan, W. Wang, J. Zhang, L. Peng and A. Wang, Chem. Eng. J., 2015, 262, 390-398.

31 J. Fu, Z. Chen, M. Wang, S. Liu, J. Zhang, J. Zhang, R. Han and Q. Xu, Chem. Eng. J., 2015, 259, 53-61.

32 Y. Qiu, H. Cheng, C. Xu and G. D. Sheng, Water Res., 2008, 42, 567-574.

33 J.-H. Yuan, R.-K. Xu and H. Zhang, Bioresour. Technol., 2011, 102, 3488-3497.

34 G. L. Dotto, J. M. N. Santos, I. L. Rodrigues, R. Rosa, F. A. Pavan and E. C. Lima, J. Colloid Interface Sci., 2015, 446, 133-140.

35 A. M. M. Vargas, A. L. Cazetta, M. H. Kunita, T. L. Silva and V. C. Almeida, Chem. Eng. J., 2011, 168, 722-730.

36 S. Mandal, E. Donner, S. Vasileiadis, W. Skinner, E. Smith and E. Lombi, Sci. Total Environ., 2018, 627, 942-950.

37 M. A. M. Khraisheh, M. A. Al-Ghouti, S. J. Allen and M. N. Ahmad, Water Res., 2005, 39, 922-932.

38 X. Tan, Y. Liu, G. Zeng, X. Wang, X. Hu, Y. Gu and Z. Yang, Chemosphere, 2015, 125, 70-85.

39 D. Mohan, S. Rajput, V. K. Singh, P. H. Steele and C. U. Pittman, J. Hazard. Mater., 2011, 188, 319-333.

40 S. Rangabhashiyam, N. Anu and N. Selvaraju, J. Environ. Chem. Eng., 2013, 1, 629-641.
41 J. M. Novak, I. Lima, B. S. Xing, J. W. Gaskin, C. Steiner, K. C. Das, M. Ahmedna, D. Rehrah, D. W. Watts and W. J. Busscher, Ann. Environ. Sci., 2009, 3, 195-206.

42 K. Rida, S. Bouraoui and S. Hadnine, Appl. Surf. Sci., 2013, 83-84, 99-105.

43 H. Zhu, T. Chen, J. Liu and D. Li, RSC Adv., 2018, 8, 26162621.

44 X. Han, W. Wang and X. Ma, Chem. Eng. J., 2011, 171, 1-8.

45 M. Shirmardi, N. Alavi, E. C. Lima, A. Takdastan, A. H. Mahvi and A. A. Babaei, Process Saf. Environ. Prot., 2016, 103, 23-35.

46 M. M. Hamed, I. M. Ahmed and S. S. Metwally, J. Ind. Eng. Chem., 2014, 20, 2370-2377.

47 J. Z. Guo, B. Li, L. Liu and K. Lv, Chemosphere, 2014, 111, 225-231.

48 S. Fan, Y. Wang, Z. Wang, J. Tang, J. Tang and X. Li, J. Environ. Chem. Eng., 2017, 5, 601-611.

49 M. El Achaby, N. Fayoud, M. C. Figueroa-Espinoza, H. Ben youcef and A. Aboulkas, RSC Adv., 2018, 8, 5212-5224.

50 H. Sheng, F. Wang, C. Gu, R. Stedtfeld, Y. Bian, G. Liu, W. Wu and X. Jiang, RSC Adv., 2018, 8, 9364-9374.

51 A. Suddai, P. Nuengmatcha, P. Sricharoen, N. Limchoowong and S. Chanthai, RSC Adv., 2018, 8, 4162-4171.

52 S. Fan, J. Tang, Y. Wang, H. Li, H. Zhang, J. Tang, Z. Wang and X. Li, J. Mol. Liq., 2016, 220, 432-441.

53 L. Shi, G. Zhang, D. Wei, T. Yan, X. Xue, S. Shi and Q. Wei, J. Mol. Liq., 2014, 198, 334-340.

54 M. S. Sajab, C. H. Chia, S. Zakaria, S. M. Jani, M. K. Ayob, K. L. Chee, P. S. Khiew and W. S. Chiu, Bioresour. Technol., 2011, 102, 7237-7243.

55 M. E. Fernandez, G. V. Nunell, P. R. Bonelli and A. L. Cukierman, Bioresour. Technol., 2010, 101, 9500. 